$\begin{array}{ll}\text { ISSN } & \text { 0975-6795 (Print) } \\ & \text { 2321-5828 (Online) }\end{array}$

DOI: $10.5958 / 2321-5828.2021 .00004 .8$

Vol. 12 |Issue-01|

January - March| 2021

\author{
Available online at \\ www.anvpublication.org \\ Research Journal of \\ Humanities and Social Sciences \\ Home page www.rjhssonline.com
}

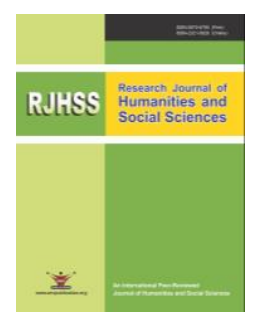

$\underline{\text { RESEARCH ARTICLE }}$

\title{
Finding Concepts with Sexuality and Making Sense of Social Institutions in Foucauldian Perspective
}

\author{
Anil Kumar \\ Assistant Professor of Sociology, Central University of Kashmir, India. \\ *Corresponding Author Email: vipanil@ gmail.com
}

\begin{abstract}
:
In this paper, an attempt has been made to discover the key concepts in Foucault's philosophy. The author tries to highlight the Foucauldian perspective as unique. There is an attempt to establish a relationship between the concepts and the concerns of sexuality. Furthermore, there are references to some of the social institutions to justify this relationship while concluding with an emphasis on the relevance of sex education in society.
\end{abstract}

KEYWORDS: Foucault, Foucauldian Perspective, Sexuality, Social Institution, Sex Education.

\section{INTRODUCTION:}

Michel Foucault, the French philosopher and historian of the systems of thought, strongly influences almost every discipline in the field of humanities and social sciences. He became extraordinarily popular through his incomparable writings and series of lectures which have been recorded and also published in various forms. Not only he could extend his capacities to make sense of the politics but also gave a unique shape to the postmodern literature. Contemporary and later scholars often recognise Foucault as a poststructuralist and postmodernist scholar. He touched societal issues in his works from a unique perspective. Instead, his approach became a significant perspective in itself, say Foucauldian perspective. Foucault highlighted the problems involved in diverse social institutions, viz., economy, polity, knowledge, power, sexuality, religion, culture and even health and psychiatry.

\section{Power-Knowledge relationship:}

Foucault believes that a social structure is micro-politics of power. Knowledge-power relationship is Foucault's significant contribution to postmodernism. Almost every concept of Foucault is engulfed in power and knowledge relationship. Foucault expresses his opinions by explaining that power and knowledge entail one another and knowledge has lost its value and has become enslavement. It has ceased its liberation. Foucault believed that power emerges from different exercises of daily life (Pylypa, 1998). Whatever happens in the society, it all happens due to the power-knowledge relationship. It is pertinent to mention that the central theme of Foucault's work stays within the field of epistemology. His original wish was to study knowledge that he found rooted in power. It is the power which empowers knowledge. Foucault (1978: 5) has thus established a well-designed relationship between power, knowledge and truth. Power is present in society in various forms, and it is always in circulation.

\section{Discourse:}

Another essential feature or theme of Foucault's work is discourse. He opined that power, knowledge and truth are connected through discourses and texts (Ibid.). By discourse, he meant a social institution, disciplines such as crime, corruption, leadership, village, development, industrialisation, capitalism and environment (Ibid., 143). Discourse is everywhere, and it keeps on changing. 
An example he quoted is family. It is a discourse, but it has changed its structure over time. Foucault wanted to make it clear that discourse does not only come in abstract ideas and images but in concrete forms too. Through discourse, he has presented the concept of sexuality as well. He affirms that it is the discourse that distinguishes proper and improper sexual conduct. It changes from culture to culture.

If Foucault mainly concentrated on the three concepts, viz., knowledge, power and truth, he identified a relationship between them in all of his significant works but primarily in The Archaeology of Knowledge and the first volume of The History of Sexuality (which is also an impression of the 'genealogy of power'). It has to be ascertained more specifically that genealogy offers us a procession perspective on the web of discourse and archaeological approach provides us with a snapshot, a slice through the discursive nexus. Foucault is known for his sympathetic attitude towards marginalised sections of society (for example, artists, queers, prisoners, patients). Perhaps, he was influenced by Jean-Paul Sarte and had repulsion towards the bourgeois class.

\section{Education:}

Foucault's works on madness, punishment, sexuality and the human sciences have provided new concepts to the pedagogical field and overall academics. Ideas like discipline, problematisation, archaeology, genealogy have unfolded various hidden issues in the education system. Foucault's works are diverse but inclusive. Within their broader spectrum, they incorporate domains which ultimately become (essential) subject matter in the field of education (Deacon, 2006).

Foucault's works have significant characteristics that make them different from all other authors. Foucauldian concepts, methods and arguments enhance the curiosity of any learner or a scholar. Foucault has been able to suggest formulations of a realistic strategy along with theoretical and philosophical techniques to examine the normal functioning and outcomes of connections between power, knowledge and discourse (Ibid.). It is obligatory to know that Michel Foucault has not devoted a particular work on education as he did in other fields. Still, he has sensibly integrated most of his ideas with educational practices.

\section{SEXUALITY AND SOCIETAL CONCERNS:}

Foucault (1978: 3) argued that by the time of the 19th century, with the advancement (of science and technology) and an increase in the population, the administration became aware of the fact that they have to run a community, not subjects. It forced them to take account of births, deaths, marriage and other related institutional aspects. It was just a beginning, ultimately leading to a new and different field of study in the name of sex and sexuality. By the end of the 17th century, the outlook of people was gradually changing. The sexuality was seen confined up to married couples, and only issues related to the marriage were taken into account. Foucault argues that in the early 18th century and afterwards, society ceases discussing the sex lives of married couples and more focus, attention and discussion was put on the issues of sex and sexuality outside to married life. This field was collectively referred to as the "world of perversion' (including the sexuality of children, lunatics, criminals, homosexuals and transgender people). According to Foucault, it led to the three significant effects on society. There came a new group into existence (recognition) and was named as 'homosexuals'. This group of people engaged in samesex activities. They were considered a burden in society and ill-treated. They were treated with severe punishments as the norms of the day would consider it a big sin. Second Foucault argued that labelling of perverts conveyed a sense of 'pleasure and power' on to both parties (those studying and the perverts themselves). The last thing he argues is that the bourgeois society exhibited blatant and fragmented perversion.

\section{Will to Knowledge:}

The 'will to knowledge' is one of the critical concepts in The History of Sexuality by Michel Foucault. Through this study, Foucault has examined the emergence of "sexuality" as a discursive object and a separate sphere of life. According to Foucault (1978: 12), there is a developing notion that every individual has sexuality (a recent development) in western societies. The first volume of The History of Sexuality (the will to knowledge) mainly deals with Foucauldian criticism of the 'repressive hypothesis' (Ibid., 12-49). Repressive hypothesis entails the idea that sexuality was suppressed due to the rise of capitalism and bourgeoisie from the seventeenth to the mid-twentieth century in the western world. He believed that the discourse on sexuality emerged during this period when experts and other associates began to examine sexuality scientifically. They enforce people to confess their sexual feelings and other natural and required desires (actions). According to Foucault, it was during the 18th and 19th century that societies took an increasing interest that was different from routine procedures being outside the marital bond (as mentioned elsewhere the 'world of perversion').

Foucault refers to 'repressive hypothesis' which can be understood as a thought or belief in the early periods that westerners repressed the concept of sexuality and open discussion on sex. It was believed that most of the people from the west were not in favour of open discussion on sex. Then it was followed by the partial liberation of sexuality with the advancement of knowledge and awareness. Foucault argues that sexuality was never reserved, but it looked like that because it was 
in control of so-called repressive power. Further, Foucault says that from the 17th century onwards, there has been a genuine outburst in the discussion of sex (Padgug, 2007). The main intentions were what one could talk and with whom. Foucault (1978: 34) states that it was during the mid-eighteenth century when there was a surfacing of a political, profitable, and scientific incitement to talk about sex and issues related to sexuality. The experts from different fields spoke in good morals and real perspective on sex and sexuality concerns. It also led to the categorisation of sex later on.

Foucault (1978: 55) further says that the development of the scientific study of sex (to unearth the truth of sex and sexuality) became popular in the west. He argues that before that, there were different racial discrimination based on sex from different norms and rules of the society. The church was one of the significant authority to decide on the issues related to sex and sexuality. Slowly the reformation brought a drastic change in the attitude among the people, and that paved the way for confession. It made possible that child and parent, doctor, educator all understood the importance of sexuality issues and thereby gave it due importance. By the 19th century, the truth of sexuality was being explored both through confession and scientific enquiry (Ibid., 65).

To elaborate on this concept further, Foucault explores the question of why western society was more interested in seeking the truth of sex. He argues that there is a need to develop analytics of power through which the nature and importance of sex can be understood (Dale, 2011). Foucault believes much in the authority that power holds. The establishment of rules is possible through the power that ultimately influences the truth behind sex. Foucault argues that it is only through the power that demands obedience through domination, submission and subjugation (Ibid.). He has sought examples from Europe where they thought that power is necessary to maintain law, order, and peace.

Foucault was totally in disagreement with the western people for believing that power emanates from the law. $\mathrm{He}$ affirmed that we must construct analytics of power that no longer takes law as a model and a code (Ibid.). Foucault thought that another power governs sexuality not that we practice in the form of laws and rules. There is an understanding of it through Foucault (1978: 91) that is "We must at the same time conceive of sex without the law, and power without the king'. The concept of power has been explained in detail by Foucault. He defines it as not the domination or subjugation exerted on society by the government or by the state. Instead, it should be understood as the multiplicity of force relations immanent in the sphere in which they operate (Ibid., 92). He argues that power comes from everywhere.
'Will to knowledge' is therefore totally dedicated to the brutal treatment of sex in society. The concept of sexuality can be elaborated more from the Foucoudian point of view by integrating with the idea of society, freedom, religion, morality and rights.

\section{Society:}

Society, from Foucauldian point of view, consists of different classes such as capitalists, the needs of national states, the struggle of workers, the arguments of educational reformers or the general progress of the individuals (Ibid., 121). Society is a total of all the institutions that work together. It is dominated mainly by education (school) as per the perception of Foucault. It was believed that family and the field of work dominate the functioning of society, but from the Foucault's perception, it is the school that affects more than others. Although education was not the only source of knowledge, the ways and behaviours of society were dominated as per the schooling of the system. Before the nineteenth century, the practices in society were more or less strict, reserve, and rigid. Such character made society more complex and less participatory in functioning. Foucault analysed different aspects and areas to understand the means and ways that affect the smooth functioning of society as has been explained and perceived that society is not dependent on one factor. Still, it is being influenced by various other factors also. To understand the crux and factors, Foucault points out some interesting hints and reasons that can help one to know the mechanism of society.

The different correlations between tendencies towards individualisation and totalisation: each differently utilises time, divides space, establishes institutions, produces knowledge and regulates subjects all amalgamate human capacities relations of communications and relations of power all seek to alter those who are confined fundamentally, and all have lateral effects extending beyond themselves (Deacon, 2006).

It has been viewed that brute force was used to solve all the problems of society. Then came the period when schools came in the rescue. Schools function with honesty and with the intent of the rehabilitative activity. It is mainly to contain disorder and neutralise dangers and were justified in terms of their presumed capacity to prevent ignorance, idleness and insubordination (Foucault, 1978: 124). The corrupt churches mostly ran society. Hard rules were followed despite being opposed to the wishes and whims of the majority of the public. There was no discipline at all that led to the protest by the working class. Then there was a revival and came the time with the change in the attitude and increase in the education system, awareness force people to accept the realities. It led to a waning of mainstream churches, the 
decline of guiding system etc. The education system underwent a revival, and the practices that were dominated with the traditional ways were replaced with more positive attitudes. It was seen that the education system was going through 'the lack of regulation associated with a lack of humanity or from the Foucauldian point of view with a poor economy of coercion' (Ibid., 138). It was dominated with corporal punishment rather than considering the shortcomings in the methods of instruction, textbooks, curriculum etc.

Michel Foucault was against all these things and wanted to have a new society that contributes towards the positive attitude of its institutions. He believed that free men are both more productive and more malleable than slaves rubbed shoulders with the conservative view that existing social hierarchies would be upset were a commoner teacher to beat a noble pupil (Ibid., 141). Foucault suggested that the concern was less about inhumanity or violence per se and more about the kind or degree of power. The consequences of the restrictions and harsh attitudes produced stricter surveillance, accumulated knowledge and tighter portioning. They had made possible, but it did not ensure greater social control, these effects had also rendered more visible and problematic the rather unwieldy functions of existing schooling (Ibid., 126). Some particular religious groups used their power to control the proceeding and produce more effective results. They used their approach to use these means as a weapon for self-defence.

\section{Freedom:}

Michel Foucault is one of the renowned contemporary philosophers who has never been in any pressure to hide emotions and expressions. In his works, he has portrayed a society in its real context. For Foucault, freedom is limited to some individuals. The rules and regulation in the community are governed by the power that is in some hands. Freedom has various dimensions, and previously it was limited to some areas. Foucault was the one among the latest new generation thinkers who highlighted the problems of marginalised section of the society. Earlier one group of individuals who belong to neither male nor female were being treated harshly. Here in this section, the investigator focuses on the freedom of an individual concerning sexuality.

Sex and sexuality were never in the audience during the early times. However, with the advancement and awareness, people began to realise the need and importance of sexuality. There was repression in society; still, sexuality was at its peak but not in public, in private. Foucault argues that it was during the start of the 19th century that most of the western countries began to look for the need of care for sexuality. As per Foucault, sexuality has been limited to some particular concepts but in its real essence sexuality is one of the natural gifts bestowed to all. Being himself sexually different from the normal ones Foucault was well aware of the freedom he had enjoyed in his life. Freedom for Foucault means right to enjoy what is being bestowed by nature and that we cannot control. To make it more understandable, Foucault wants to bring the attention of society toward the group of individuals who were marginalised because they were not part of either of the two sexes (male and female). This folk of people in society were different from the rest in enjoying their desires. They were at that moment referred to as 'third gender people' or 'homosexuals', and now with the time, they have been further classified into different categories. Foucault is known as one of the first thinkers who laid a platform for this group of people. Foucault argues that they should be provided all those facilities and other incentives as others do enjoy. They should be allowed to live as feel satisfied. A particular section, and not everybody, framed and controlled the rules and laws in the society. Foucault believes that there should be a proper scope of provisions for homosexuals and other deprived sections. He has mentioned some of the severe punishments that were labelled for this group of people. There was no scope of freedom at all.

Gender deviant (third gender or homosexual) would be deprived of freedom in society. They are not readily accepted. There are various reasons for that. Nevertheless, the summation of all that is that the third gender is at the receiving end. The only solution to this menace is to provide sexual awareness to children and common masses. Two ways one can do it; first, we need to provide sex education at home and then at schools. By giving sex education to children at large, awareness can be provided so that the fixed taboos and other unnecessary restrictions can be eradicated. When we speak of freedom, it is right of every individual to live a dignified life. However, what we see in society, it is still far away, a dream. One of the fundamental rights is the right to education, and it should include all the dimensions, not a few. The condition of our society is pathetic, and there is a need for change to accept the realities. We are living in the modern world but with obsolete thoughts, and that cannot help us to compete at the world level. There is an immediate need for change, and it has to be started from the home. Sex education can help us in many ways. It can help children to protect themselves and make them self reliable. They can feel more freedom by enjoying as per their desires.

The attitude can be shaped in a way where there will be the least scope of discrimination. Different sexes will understand the natural phenomenon at the onset and will accept all equally. There will be less repulsion among the sexes. Most of the people who feel repressed can enjoy freedom from the beginning. Foucault has explained that freedom means life and life is freedom. 
Time has come to accept the change, and everybody should feel a sense of acceptance, not rejection.

\section{Religion:}

Michel Foucault had the least influence of religion throughout his career. He respected all the religions, but he was not satisfied with the proceedings and dealings of faith. He had keenly observed the practices and rules and laws framed by the heads of the religions. He was very fond of the principles of the religion but at the same time had lost faith because the preachers of the religions were ruling the oppressed class as per wishes. It was confined to a particular group. There were harsh sanctions for those found guilty. Also, many times innocents were being targeted. What affected most Foucault was that all the religions were not supporting the marginalised or deprived sections. Third gender people, women and children were being ignored, and there was the least importance given at the teachings related to some serious issues like sexuality etc. some of the fundamentals were being deprived. Religion was dominant at the time of sanctions and punishment. Foucault had a different opinion that was close to Karl Marx that religion had been created by some of the fundamentalists to enjoy their lives at the mercy of others. There was no balance of laws and rules in faith. Power was being misused. Churches were at the helm of affairs, but in action, there were many flaws and loopholes.

Foucault argues that those countries that were not confined to religion had a bright future, and they advanced at a rapid rate. They had a different attitude, and that enabled them to progress. While relating sexuality with the religion, Foucault was angrier at the practices of faith. There was no scope or provision of discussing issues related to sex in churches or religious places. Females were treated as inferiors only because of their different sexes. The third gender was being treated like animals, and there was no law for their safety or freedom. The practice of doing sex by homosexuals was considered as a big sin, and they were given severe punishments. There was no freedom of expression in religion from the sexual point of view. The concept of sexuality was limited to marriage only, and nobody could dare to express anything about it. There was no awareness provided in religion regarding sexuality and the natural changes in the body related to the same.

To brief, Foucault did have faith in religion, but it was not practised in the right manners that compelled him to be away from religion. His works are more open and had little or no influence of any conservative force.

\section{Morality:}

Ethics is one of the issues that has been highlighted by Foucault. Morality is the sum of the fair values and the conduct of a particular society. Many of Foucauldian concepts are sensitive and keeping in view the value system they were also criticised at large. To make it more precise and understandable, here we refer to sexuality and morality in the writings of Foucault. Earlier sexuality was considered as a severe issue in the context that hardly people were allowed to talk about any problems related to it. In general, it was deemed to be immoral if anyone would talk about sex. It was a value system formed in society by the misuse of power. The value system was fixed to a particular group in the society who were ruling majority. People were afraid of speaking about sexuality issues and if found violating rules were being penalised at most. However, it was seen in a society that crime rate from sexual practices was at its peak, but it was being done all under the curtains. Nobody was allowed to speak in the open, but many would enjoy freely behind the scenes. Foucault studied all such practices and the value system that was being in the way and concluded that it is totally against morality.

Morality is not to oppress or suppress but to guide and provide requisite provisions for the right to life. It is a birthright to provide all the facilities to an individual as per their need and also considering the demand of society. Nevertheless, what was observed in the society was opposite of reality. People were being targeted, and a few were enjoying at the mercy of the majority. The basic rules and laws for morality were being established as per the choice of few and not for the smooth functioning of the society. If one tries to establish a relation in Foucault's writings between sexuality and morality, one will find relatively different results. Foucault believed that morality does not mean we have to oppress a particular identity for being different from the majority. Sexuality is a natural gift, and we cannot control it as per our wishes but what we can do is to accept it in general. If we can provide safety and security to all the individuals in the society irrespective of their sexes, morality will automatically be functional. To be moral does not mean not to discuss sex, sexuality and other related issues. Still, it points to discuss all those things that are necessary for the beneficial of the society. The best recommendation for this is to provide sex education in schools as well as in homes from an early age. It may help in bringing an attitudinal change among the new generation. Foucault has stressed on this issue only for the upliftment of marginalised section, especially third gender and women. Most of the Foucault's ideas are in and around the umbrella of morality.

\section{Rights:}

A right is something perfect for all. It can never be harmful or hazardous to society or any individual. In general context rights are bestowed from the conception and last till death. They are present in diverse forms. Seeing rights through the Foucauldian perspective means 
bearing in mind civil liberties under the cover of Michel Foucault's writings. Foucault, as we have read him, was a different thinker, a philosopher. In a discussion on sex education, we deal with the importance of sexuality and the teaching of sex education. Sexuality, during Foucault's times, was being considered as a taboo. There were harsh rules and regulations related to sexuality.

Foucault was upset with that system, and the same he presented in his famous work, particularly in the first volume of The History of Sexuality. From a generalistic point of view, we can say that sexuality has its rights. These rights start from providing awareness and the right knowledge to children from the beginning of the sexual instincts. Sexuality has different functions to perform like the continuity of life, sexual health, pleasure etc. all these things come under one ambit that is right; everyone has this right to enjoy. Still, it is not happening in the real context. There is discrimination based on sex, as well. Among categories of gender, one is considered superior another inferior and rest has no right to live with dignity. Foucault witnessed the harsh treatment with the others who are outside the boundaries of superiority and inferiority. They are strictly excluded. Through Foucauldian analysis, there is a clear message that there were no satisfactory rights for some and no rights at all for the rest. The rights that existed got diluted in practice due to the dominance of power in a negative sense. Foucault started an initiative providing a platform for discourse, especially to those who were being ill-treated. $\mathrm{He}$ gave them recognition through his art. Foucault believes that sexuality is itself a birthright and there is a need to provide a conducive environment so that the desires and wishes that are natural, innate and necessary for a good state of health, can be fulfilled.

\section{CONCLUSION:}

To conclude, from a Foucauldian perspective, that power is responsible for the repression of sexuality is utterly truthful. The main idea of Foucault has been that we need to accept sexuality from the realistic perspective as it is an endowment from nature. The classification of sex, the dominance, the rules etc. all are just imaginary constructs by some superior power. The society has been divided into unrealistic matters. Some are considered dominant, and others inferiors, it all leads to crime and violence. The only remedy for all such acts is to accept reality, and there is a need for bringing change in attitudes towards sexuality. Sexuality is same as other biological phenomena, and we need to provide awareness among the masses in the developing or underdeveloped part of the world. Just like some of the western countries who started the initiative, the others need to follow them. There should be a proper procedure for the introduction of sexuality discipline in the curriculum that can fulfil the essential needs of the children.
Foucault argues that a society with good morality, religion, culture, human rights, and other useful values is possible only when there are justice and equality. One of the first step to achieve all these things is to provide helpful information about sexuality and accept it as a uniform phenomenon. The attitudinal change is must, and that can be done only with the introduction of sex education in homes and schools. Family and schools are both responsible for this. Talking about sex should not be taken anymore as a taboo or invite punishment. From Foucault's lens, most of the concepts concerning sexuality are without any bias or harsh law, and likewise, they must progress.

\section{REFERENCES:}

1. Dale, William (2011), "Foucault's Sexuality", The Atlas Society, https://www.atlassociety.org/post/foucaults-sexuality [Accessed 18.02.2018].

2. Deacon, Roger (2006), "Michel Foucault on Education: a preliminary theoretical overview", South African Journal of Education, Vol. 26, No. 2, pp.177-187.

3. Foucault, Michel (1978), The History of Sexuality (Volume I: An Introduction), Translated from the French by Robert Hurley, New York: Pantheon Books.

4. Padgug, Robert A. (2007), "Sexual Matters: On conceptualising in history", (in: Richard Parker and Peter Aggleton - Ed., Culture, Society and Sexuality: A Reader), New York: Routledge, pp.17-30.

5. Pylypa, Jen (1998), "Power and Bodily Practice: Applying the Work of Foucault to an Anthropology of the Body", Arizona Anthropologist, Vol. 13, pp.21-36. 